\title{
PReS-FINAL-2347: Does switching anti-TNFA biologic agents an effective option in childhood chronic uveitis: the evidence from a systematic review and meta-analysis approach
}

\author{
${\text { G Simonini }{ }^{*}, \text { K Druce }^{2}, \text { R Cimaz }}^{3}$, GT Jones ${ }^{4}$, GT Macfarlane ${ }^{4}$ \\ From 20th Pediatric Rheumatology European Society (PReS) Congress \\ Ljubljana, Slovenia. 25-29 September 2013
}

\section{Introduction}

A subset of patients, of unknown percentage, fail to respond to TNF $\alpha$ blockers or are unable to tolerate these therapies and may therefore benefit from switching to another drug.

\section{Objectives}

To report the evidence regarding the effectiveness of switching to another anti-TNF $\alpha$ treatment in children with childhood autoimmune chronic uveitis (ACU), failure/refractory to the first course of anti-TNF $\alpha$ treatment.

\section{Methods}

A systematic search between January 2000 and May 2013 was conducted using EMBASE, Ovid MEDLINE, Evidence Based Medicine Reviews-ACP Journal Club, Cochrane libraries, and EBM Reviews. Studies investigating the efficacy of anti-TNF $\alpha$ therapy, as the second biologic treatment for ACU, in children ( $\leq 16$ yrs) refractory to a first course of a single anti-TNF $\alpha$ treatment, topical and/or systemic steroid therapy and at least one DMARD, were eligible for inclusion. The primary outcome measure was the improvement of intraocular inflammation, as defined by the SUN working group criteria, at $6( \pm 2)$ month follow-up on treatment.

\section{Results}

zAmong 1086 identified articles, 128 were scrutinized: 10 observational studies, 7 on Adalimumab (ADA), 4 on

'Rheumatology Unit-Department of Pediatrics, A.Meyer Children's Hospital University of Florence, Firenze, Italy

Full list of author information is available at the end of the article
Infliximab (INF), were deemed eligible, including 40 children (ADA $n=34$, INF $n=6$ ). JIA was the most common disease: 39 out 40 cases (97.5\%).Seven-teen children received Etanercept: 11 were switched to ADA, the remaining 6 to INF. All the 23 children previously received INF were switched to ADA. Altogether, 30 children (24 on ADA, 6 on INF) out of 40 responded to treatment, and the proportion of participants with a positive response ranged from $43 \%$ to $100 \%$ individual studies.The pooled analysis suggested that a second anti TNF $\alpha$ treatment with ADA and INF has a favorable effect in the improvement of intraocular inflammation: 0.75 (95\% CI: 0.67-0.81) was the combined estimate of the proportion of subjects improving All 6 children who received INF after a previous failure to a course of ETA, responded. Eight out of eleven $(72.7 \%)$ children with a previous failure ETA, and 16 out 23 (69.5\%) with a previous failure to INF, responded to a second course of anti TNF $\alpha$ treatment with ADA.Eighteen chidlren on ADA and all 6 on INF have been able to tape and/or discontinue systemic steroid administration; discontinuation/tapering of concomitant DMARD therapy was possible for 7 out of 19 children receiving ADA, 3 out of 4 children receiving INF. Four eligible papers did not report extractable data regarding visual outcome. Nine of 11 children $(73 \%)$ showed improvement or stable normal visual acuity post ADA treatment, and 5 out of 6 children (79.3\%) after INF. Among 33 anti-TNF $\alpha$ exposed children, data regarding side effects were not available from 2 studies $(\mathrm{n}=7), 6(25.2 \%)$ experienced adverse events: 5 while on ADA (all 5 complaining pain discomfort and/or local reactions), 1 on INF, who experienced a transient broncospastic cough. 


\section{Conclusion}

Switching between anti-TNFa obtains an overall probability of improvement of intraocular inflammation in $75 \%$ children affected by refractory ACU. No switching has been reported to ETA, all children received ADA or INF after the first anti TNF $\alpha$ failure.

\section{Disclosure of interest}

None declared.

\section{Authors' details}

'Rheumatology Unit-Department of Pediatrics, A.Meyer Children's Hospital University of Florence, Firenze, Italy. ${ }^{2}$ Musculoskeletal Research ProgrammeEpidemiology Group, Institute of Applied Health Sciences, University of Aberdeen, Aberdeen, UK. ${ }^{3}$ Rheumatology Unit-Department of Paediatrics, A. Meyer Children's Hospital,University of Florence, Firenze, Italy.

${ }^{4}$ Musculoskeletal Research Programme-Epidemiology Group, Institute of Applied Health Sciences, University of Aberdeen, Aberdeen, UK.

Published: 5 December 2013

doi:10.1186/1546-0096-11-S2-P337

Cite this article as: Simonini et al:: PReS-FINAL-2347: Does switching anti-TNFA biologic agents an effective option in childhood chronic uveitis: the evidence from a systematic review and meta-analysis approach. Pediatric Rheumatology 2013 11(Suppl 2):P337.

Submit your next manuscript to BioMed Central and take full advantage of:

- Convenient online submission

- Thorough peer review

- No space constraints or color figure charges

- Immediate publication on acceptance

- Inclusion in PubMed, CAS, Scopus and Google Scholar

- Research which is freely available for redistribution

Submit your manuscript at www.biomedcentral.com/submit 